\title{
Erratum to: Characteristics and Outcomes of Methicillin- Resistant Staphylococcus aureus Surgical-Site Infections in Patients with Cancer: a Case-Control Study
}

\section{Roy F. Chemaly, MD, MPH ${ }^{1}$, Ray Y. Hachem, MD ${ }^{1}$, Rola N. Husni, MD ${ }^{1,5}$, Boulos Bahna, MD ${ }^{1}$, Georges Abou Rjaili, $\mathrm{MD}^{2}$, Alain Waked, $\mathrm{MD}^{2}$, Linda Graviss, MT, CIC ${ }^{1}$, B. Nebiyou Bekele, PhD ${ }^{3}$, Jharna N. Shah, MD ${ }^{1,4}$, and Issam I. Raad, MD}

${ }^{1}$ Department of Infectious Diseases, Infection Control and Employee Health, Unit 402, The University of Texas M. D. Anderson Cancer Center, Houston, TX; ${ }^{2}$ Department of Internal Medicine, Staten Island University Hospital, Staten Island, NY; ${ }^{3}$ Department of Biostatistics, The University of Texas M. D. Anderson Cancer Center, Houston, TX; ${ }^{4}$ University of Texas Health Science Center at Houston, School of Public Health, Houston, TX; ${ }^{5}$ Department of Infectious Diseases, Rizk Hospital, Beirut, Lebanon

\section{ERRATUM TO: ANN SURG ONCOL DOI 10.1245/S10434-010-0923-5}

The author byline of the published article entitled, "Characteristics and Outcomes of Methicillin-Resistant Staphylococcus aureus Surgical-Site Infections in Patients with Cancer: A Case-Control Study" included an error in the spelling of the following author's name: Abou Rjaili G, MD.
The correct author byline for this article is:

Roy F. Chemaly, Ray Y. Hachem, Rola N. Husni, Boulos Bahna, Georges Abou Rjaili, Alain Waked, Linda Graviss, B. Nebiyou Bekele, Jharna N. Shah and Issam I. Raad

This article was published online February 2, 2010.

The online version of the original article can be found under doi:10.1245/s10434-010-0923-5.

(c) Society of Surgical Oncology 2010

Published Online: 12 March 2010

R. F. Chemaly, MD, MPH

e-mail: rfchemaly@mdanderson.org 